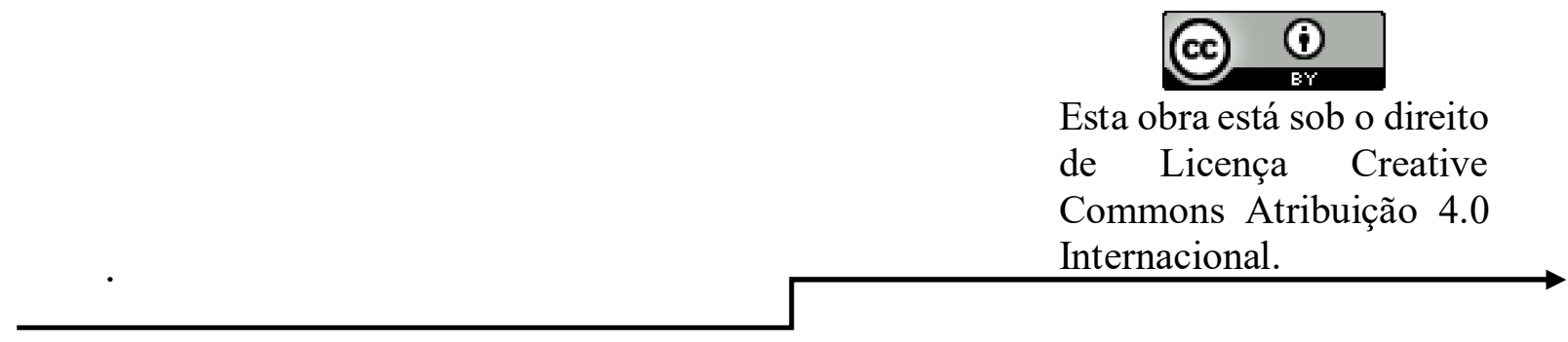

\title{
O YOUTUBE COMO FONTE DE PESQUISA DE PROGRAMAS, PROJETOS E AÇÕES, NO COMBATE A EVASÃO ESCOLAR
}

\author{
Justina Pacheco de Vasconcelos ${ }^{1}$ \\ Andrea Marques Vanderlei Fregadolli ${ }^{2}$
}

\section{RESUMO}

Objetivo: Fazer um estudo etnográfico virtual no YouTube, sobre métodos de contenção da evasão escolar no ensino básico. Método: trata-se de um estudo etnográfico virtual, no sítio de compartilhamento de vídeo do YouTube. O período de coleta dos dados foi no mês de setembro de 2019, e adotou-se como critérios de inclusão: vídeos de 1 a 5 minutos (free), publicado nos últimos 5 anos. Enquanto que os critérios de exclusão foram: vídeos irrelevantes com a temática do estudo, repetidos e com informações inconclusivas em relação à questão norteadora. Resultados e discussão: foram analisados 104 recursos audiovisuais, entretanto, obedeceram aos critérios de inclusão apenas 45, onde 15 foram escolhidos pelo tema, para pesquisa. Quanto ao ano de publicação, seis estudos foram publicados no ano de 2019; três estudos foram publicados no ano de 2017; quatro, no ano de 2016 e um, em 2015. As categorias temáticas desenvolvidas a partir da análise dos trabalhos foram: 1- Ações a nível estadual, no combate à evasão escolar;2 - Iniciativa das secretarias de educação municipal, para contenção da evasão escolar; 3 - Ações de incentivos aos educandos, na busca da prevenção da evasão escolar. Conclusão: a pesquisa teve suas limitações, pois o uso de redes sociais, o YouTube, não dispõem de protocolos que norteiam o seu desenvolvimento metodológico, daí a dificuldade em encontrar recursos audiovisuais acerca da temática específica trabalhada. Mesmo assim contribui, no sentido de averiguar os esforços para viabilizar ações que contribui para o combate a infrequência dos educandos.

Palavras-chave: Evasão escolar. Combate. Ações.

Submetido em março de 2020 e aceito em maio de 2020.

\footnotetext{
${ }^{1}$ Possui graduação em Ciências Biológicas pela Faculdade de Formação de Professores da Mata Sul (1992).

${ }^{2}$ Doutora em Ciências (UFAL). Mestre em Modelagem Computacional do Conhecimento (UFAL). Professora da graduação de Medicina e do Mestrado Ensino na Saúde da Faculdade de Medicina (UFAL).
} 


\section{INTRODUÇÃO}

Esse artigo teve como fonte de busca o sitio da rede YouTube. Fundado por Chad Hurley, Steve Chen e Jawed Karim, em fevereiro de 2005, o sitio surgiu em virtude do inconveniente que era compartilhar arquivos de vídeo, ele permite que os usuários coloquem seus próprios vídeos na rede, sendo visualizados por qualquer pessoa no mundo inteiro. Estima-se que diariamente cerca de vinte mil novos vídeos são carregados e trinta milhões são assistidos no YouTube (Dantas, 2019). Nesse contexto o YouTube é uma ferramenta importante, pois possibilita a divulgação e compartilhamento de experiências desenvolvidas em vários conteúdos inclusive o combate a evasão escolar.

Há ainda no Brasil um grande número de crianças e adolescentes fora da escola, são 2.802.258 crianças e adolescentes de 4 a 17, segundo a Pesquisa Nacional por Amostra de Domicílios (Pnad) 2015. Essa exclusão afeta principalmente meninos e meninas vindos das camadas mais vulneráveis da população, já privados de outros direitos

\section{METODOLOGIA}

A etnografia virtual foi elegida como metodologia de investigação para adentrar a um sítio de compartilhamento de vídeos do constitucionais. Do total fora da escola, $53 \%$ vivem em domicílios com renda per capita de até $1 / 2$ salário mínimo (Unicef, 2017).

Tirar essas crianças e adolescentes desse contexto da exclusão é um desafio, daí a importância de se abrir cada vez mais espaço para discussões e reflexões, no tocante ao tema, e em particular, na educação através da pesquisa científica. Diante do exposto, propõe-se nesse artigo, fazer uma abordagem do tema através de uma pesquisa, optando-se pela a etnografia virtual como metodologia de investigação.

Contudo esta pesquisa tem o objetivo de fazer um estudo na rede do YouTube, sobre método de contenção e prevenção da evasão escolar. A escolha desta temática se deu, devido a importância de investigar as estratégias utilizadas para o enfrentamento dos autos índices de evasão escolar no ensino básico. Tendo a seguinte pergunta norteadora: Como prevenir e combater a evasão escolar na realidade educacional brasileira?

YouTube, cujo endereço virtual é: www.YouTube.com. O estudo seguiu protocolo de pesquisa composto dos elementos seguindo as seguintes etapas (ver 
tabela 1): $1^{\mathrm{a}}$ etapa - tema da pesquisa, questão norteadora, objetivo, estratégia de busca, campo de busca; $2^{\mathrm{a}}$ etapa - período das coletas, critério de inclusão e critério de exclusão dos estudos; $3^{\text {a }}$ etapa - Número de documentos áudio visuais selecionados, a partir dos critérios de inclusão e exclusão. avaliação crítica dos estudos e apresentação dos resultados com discussão; $4^{\mathrm{a}}$ etapa categorias obtidas com a análise dos vídeos; $5^{\text {a }}$ etapa - Analise, interpretação e discursão dos resultados e $6^{\mathrm{a}}$ etapa - Apresentação da pesquisa em formato de artigo, o qual contemple propostas para estudos futuros. A coleta dos dados ocorreu no mês de setembro de 2019, onde, inicialmente, no campo de busca do sítio, foi digitada a expressão elaborada pelas palavras chaves "combate a evasão escolar". Para melhor localização da amostra, foi acionado o filtro "vídeo" com classificação por "relevância", definindo-se como critérios de inclusão para a seleção dos documentos audiovisuais, reportagens de telejornais brasileiros e demais vídeos dos últimos 5 anos, com duração de 1 a 5 minutos e, de exclusão, vídeos irrelevante com a temática do estudo, repetidos e com informações inconclusivas em relação à questão norteadora.

Figura 1 - Detalhamento das etapas da pesquisa etnográfica virtual.

\begin{tabular}{|c|c|c|}
\hline ETAPA & TÓPICOS DE CADA ETAPA & DETALHAMENTO DE CADA TÓPICO \\
\hline \multirow[t]{5}{*}{$1^{\mathrm{a}}$} & Tema & $\begin{array}{l}\text { O YouTube como fonte de pesquisa de - programas, } \\
\text { projetos e ações, no combate a evasão escolar. }\end{array}$ \\
\hline & Pergunta norteadora & $\begin{array}{l}\text { Como combater a evasão escolar na realidade } \\
\text { educacional brasileira? }\end{array}$ \\
\hline & Objetivo geral & $\begin{array}{l}\text { Fazer um estudo etnográfico virtual na rede do } \\
\text { YouTube, sobre método de contenção da evasão } \\
\text { escolar no ensino básico. }\end{array}$ \\
\hline & Estratégia de busca & $\begin{array}{l}\text { foi digitada a expressão elaborada com palavras } \\
\text { chaves "Combate a Evasão Escolar". }\end{array}$ \\
\hline & Campo de busca & Sitio de compartilhamento de busca do YouTube. \\
\hline \multirow[t]{3}{*}{$2^{\mathrm{a}}$} & Período de coleta dos dados & setembro de 2019. \\
\hline & Critérios de inclusão & $\begin{array}{l}\text { 1. Vídeos (disponível/free); } \\
\text { 2. Publicação (2014-2019); } \\
\text { 3. Tempo de vídeo, de } 1 \text { a } 5 \text { minutos. }\end{array}$ \\
\hline & Critérios de exclusão & $\begin{array}{l}\text { 1. Vídeos longos; } \\
\text { 2. Irrelevantes com a temática de estudo; } \\
\text { 3. Repetidos. }\end{array}$ \\
\hline $3^{\mathrm{a}}$ & $\begin{array}{l}\text { Número de documentos áudio } \\
\text { visuais selecionados da pesquisa } \\
\text { etnográfica virtual, a partir dos } \\
\text { critérios de inclusão e exclusão. }\end{array}$ & 15 \\
\hline
\end{tabular}

Justina Pacheco de Vasconcelos \& Andrea Marques Vanderlei Fregadolli 


\begin{tabular}{|l|l|l|}
\hline $4^{\mathrm{a}}$ & $\begin{array}{l}\text { Categorias obtidas com a análise } \\
\text { dos vídeos }\end{array}$ & $\begin{array}{l}\text { 1- Ações a nível estadual, no combate a evasão } \\
\text { escolar; } \\
\text { 2 - Iniciativa das secretarias de educação municipal, } \\
\text { para contenção da evasão escolar; } \\
3 \text { - Ações de incentivos aos educandos, na busca da } \\
\text { prevenção da evasão escolar. }\end{array}$ \\
\hline $5^{\mathrm{a}}$ & $\begin{array}{l}\text { Analise, interpretação e } \\
\text { discursão dos resultados }\end{array}$ & $\begin{array}{l}\text { Ver esultados e Discursão" } \\
\text { fpresentação da pesquisa em } \\
\text { formato de artigo, o qual } \\
\text { contemple propostas para } \\
\text { estudos futuros. }\end{array}$ \\
\hline
\end{tabular}

Fonte: autoria própria.

\section{RESULTADOS}

$\mathrm{Na}$ busca, mesmo utilizando o filtro "vídeo" e classificação por "relevância" foi visualizado grandes números de documentos áudio visuais disponíveis, sendo assim optouse por averiguar os primeiros 220 (ver Figura 2). Ao selecionar os postados de 2014 a 2019, houve redução para 168 , e deixando só os vídeos com duração de 1 a 5 minutos, a redução foi para 104. Após as aplicações dos critérios de inclusão e exclusão restaram 45 vídeos, sendo selecionado para pesquisa, através do título 15 documentos audiovisuais.

Quanto ao ano de publicação, cinco estudos foram publicados no ano de 2019; dois em 2018; três estudos foram publicados no ano de 2017; quatro, no ano de 2016 e um, em 2015. Os links desses documentos foram salvos para posterior análise (ver figura 3). A nova etapa da pesquisa foi realizada a partir de visitas aos links selecionados, onde foi possível realizar as várias visitas que se fizeram necessárias, em diferentes momentos, para a observação e análise de tais documentos pré-selecionados de forma organizada. $\mathrm{Na}$ descrição dos vídeos, observou-se a data da postagem, total de visualizações e a categoria, tipo do ocorrido, data do ocorrido, logradouro do ocorrido (estado, capital ou interior), tipo de instituição que ocorreu o evento (estado, município, escola, ongs). 
Figura 2 - Fluxograma com as etapas de busca dos vídeos no YouTube.

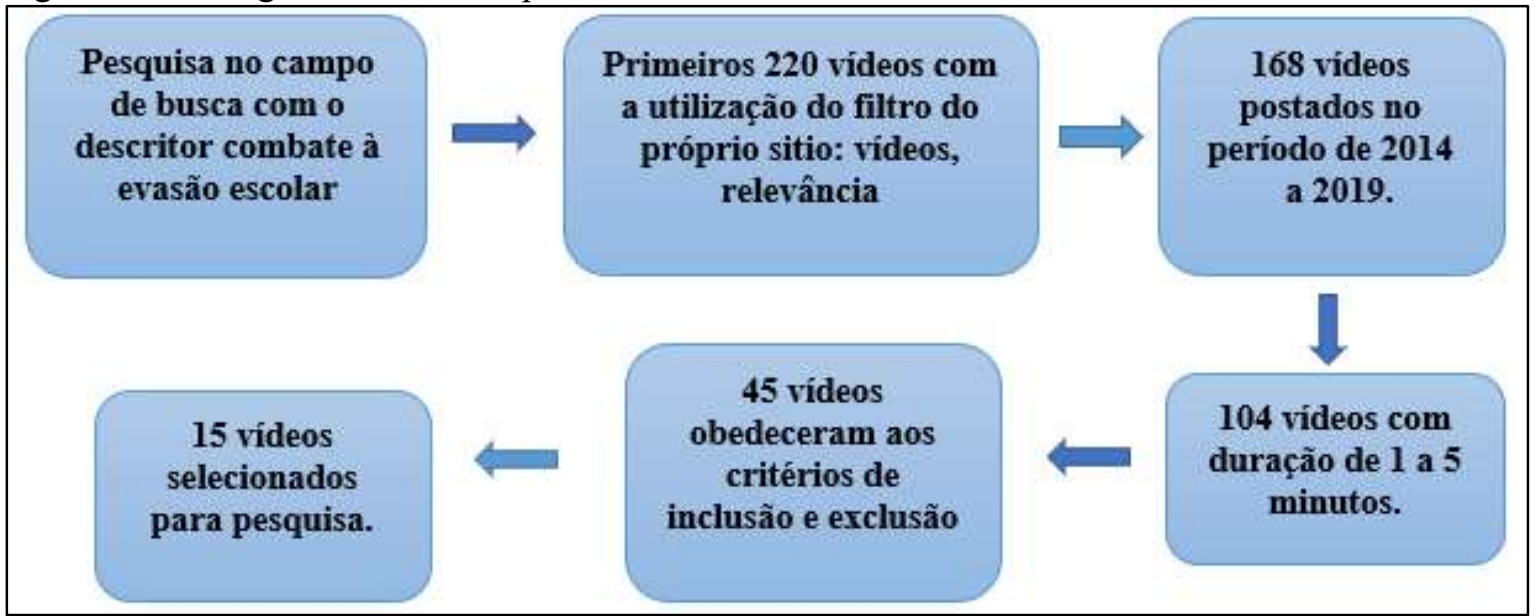

Fonte: Autoria própria. 


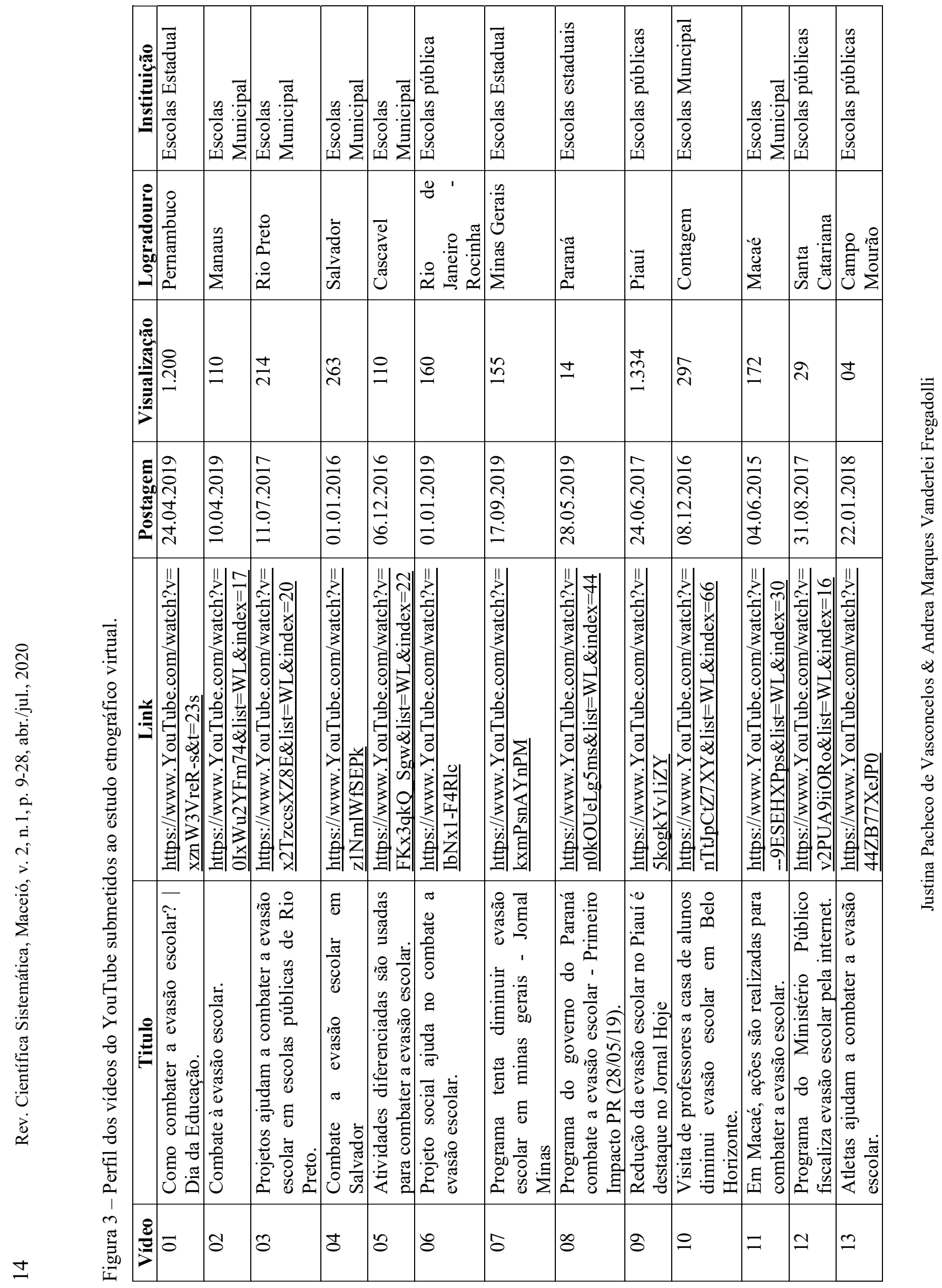




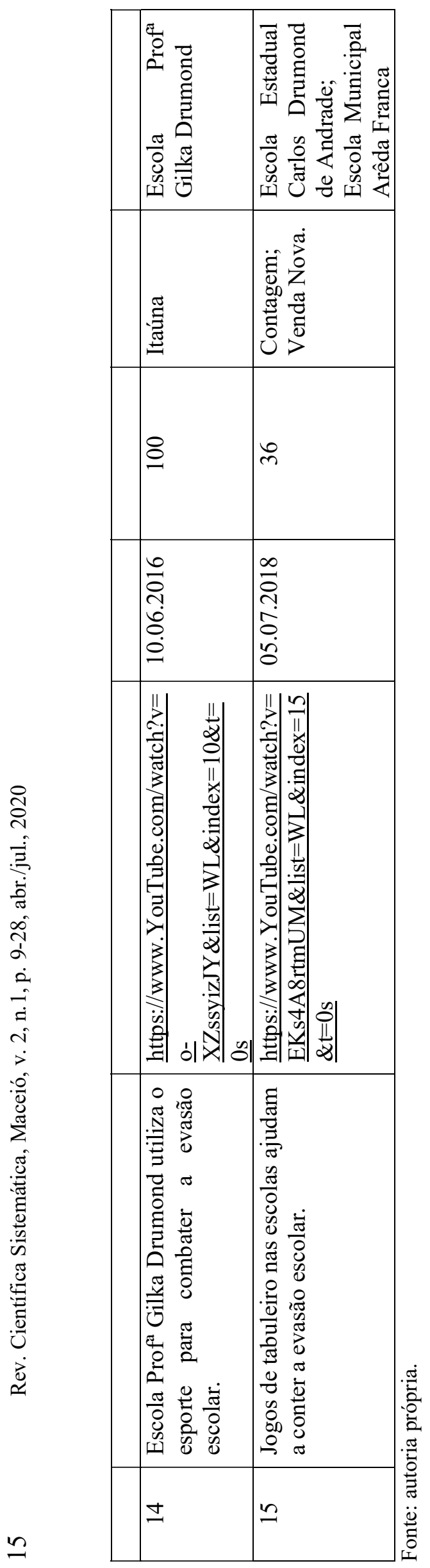

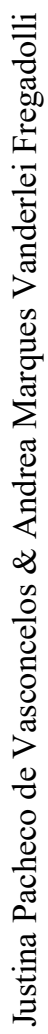




\section{DISCUSSÃO}

Foram encontrados grande números de vídeos relatando as experiências das escolas no combate à evasão escolar, com iniciativas de variados setores como: Estados; municípios; a própria escola; ministério público e entidades sem fins lucrativos. Embora não tenha sido usado como critério o fator escola pública, os vídeos disponíveis são voltados a trabalhos nas escolas públicas, e os diferentes projetos identificados sinalizam para falta de uma ação que contemplem as escolas de forma geral.

Arroyo (1991 apud QUEIROS, 2012) fala que é a escola das classes trabalhadoras que vem fracassando em todo lugar. Não são as diferenças de clima ou de região que marcam as grandes diferenças entre escola possível ou impossível, mas as diferenças de classe. As políticas oficiais tentam ocultar esse caráter de classe no fracasso escolar, apresentando os problemas e as soluções com políticas regionais e locais. Para Dourado (2005), essas questões se articulam às condições objetivas da população, em um país historicamente demarcado por forte desigualdade social, que se caracteriza pela apresentação de indicadores sociais preocupantes e, que nesse sentido, carece de amplas políticas públicas incluindo, nesse processo, a garantia de otimização nas políticas de acesso, permanência e gestão com qualidade social na educação.

Relatos e depoimento em vídeos do YouTube, sobre projetos e programas e ações que visam a contenção da evasão escolar, divididos em categoria temáticas.

\section{Ações a nível estadual, no combate a evasão escolar.}

Pernambuco (vídeo 1), tem hoje a menor taxa de evasão do país - 1,5\%, mais de $50 \%$ das redes de ensino oferece escola em tempo integral, com uma jornada entre 7 e 9 horas diárias. Além do tempo integral as escolas têm outros diferenciais como a escolha junto como os professores das matérias fora da grade curricular, que querem cursar durante o semestre, que vai desde a robótica ao empreendedorismo. $\mathrm{O}$ educando também tem um tutor, que pode ser um coordenador da escola ou um professor, o qual os jovens podem recorrer sempre que tiverem dúvidas sobre o conteúdo das aulas, questões pessoais, decisões sobre a carreira e o futuro.

A Educação em tempo Integral no estado de Pernambuco tornou-se Política Pública de Estado em 2008 (Lei complementar $\mathrm{n}^{\mathrm{o}} 125$, de 10 de julho de 2008), que em seu artigo $1^{\circ}$ cria no âmbito do Poder Executivo, o Programa de Educação Integral, vinculado à Secretaria 
de Educação, que tem por objetivo o desenvolvimento de políticas direcionadas à melhoria da qualidade do ensino médio e à qualificação profissional dos estudantes da Rede Pública de Educação do Estado de Pernambuco (PERNAMBUCO, 2008).

De acordo com Site da Secretaria de educação de Pernambuco, o modelo fundamenta-se na concepção da educação interdimensional, como espaço privilegiado do exercício da cidadania e o protagonismo juvenil como estratégia imprescindível para a formação do jovem autônomo, competente, solidário e produtivo. Desse modo, ao concluir o ensino médio nas escolas de Educação Integral, o jovem estará mais qualificado para a continuidade da vida acadêmica, da formação profissional ou para o mundo do trabalho. Contudo fica o questionamento, com apenas $51 \%$ das escolas do ensino médio em tempo integral, o possível dizer que o baixo índice de evasão escolar se deve a esta ação?

No Piauí, o governo apostou na tecnologia, segundo (vídeo 9) o estado fez registros de queda na evasão escolar nos últimos três anos de $7 \%$, depois que implantou monitoramento eletrônico de frequência escolar dos estudantes. Em Teresina 95\% das escolas conseguiram aumentar o IDEB (Índice de
Desenvolvimento da Educação Básica), também tem situação em que a escola atingiu uma frequência de 98\%. Nesse sistema cada aluno tem uma carteirinha de identificação que é apresentada todos os dias na escola e feito os devidos registros, a falta desse acarreta em uma mensagem de sms para os pais, onde são informados da ausência dos seus filhos, possibilitando por parte destes, um acompanhamento dos educandos junto a escola.

Para (SEDUC-PI) o mobieduca.me é responsável pela diminuição da evasão escolar em $13 \%$ e da infrequência em $76 \%$ nas escolas públicas da rede estadual do Piauí, o software integra consultoria tecnológica e pedagógica de acompanhamento escolar. Com a expansão da tecnologia, todos os alunos cadastrados no Mobieduca.me recebem uma carteirinha com código de barras e, ao entrar na escola, essas carteiras serão recolhidas e registradas em um leitor de código de barras. Após o registro, o sistema identifica imediatamente os alunos faltosos, alertando familiares.

Em 2018, 338 escolas já tinham este benefício e, atingindo mais de $150 \mathrm{mil}$ alunos cobertos por essa tecnologia em todo Estado. Segundo o governo do Piauí, até o final de 2019, todas a escolas estaduais estão com o sistema, que e também permite a divisão de 
responsabilidades da educação dos alunos entre a escola e a família, melhora a eficiência da gestão com dados estatísticos das escolas em tempo real e ainda atua como ferramenta auxiliar de gestão escolar.

Minas Gerais foi o único estado brasileiro que teve aumento na evasão escolar nos últimos 4 anos, com a implantação do programa busca ativa obteve-se mais de 15 mil alunos em 2019 de volta a sala de aula, mas ainda têm 60 mil fora. $O$ programa consiste na aproximação e convencimento com a família do educando, o contato pode ser telefone, mas se necessário é feito a visita na casa do jovem. As escolas também promovem atividades culturais, um meio pra deixar a escola mais atrativa (vídeo 7).

De acordo com Agência Minas, a Secretaria Estadual de Educação (SEE) tem se esforçado para reverter um quadro que vem se agravando nos últimos anos em Minas Gerais, o da evasão escolar. De acordo com o Censo Escolar 2018, 82 mil estudantes da rede estadual de ensino abandonaram os estudos durante o ano, e cerca de $75 \%$ deles são do ensino médio. Trazer o aluno infrequente de volta à sala de aula é um dos esforços e, por essa razão, a SEE optou por uma campanha de busca ativa de alunos infrequentes neste ano, para que ainda possam voltar e recuperar o tempo perdido. $\mathrm{O}$ aluno que retornar para a escola deverá ter sua frequência monitorada por meio dos lançamentos realizados no Diário Escolar Digital (DED), com o objetivo de garantir a permanência do estudante na escola. Além disso, serão realizadas intervenções pedagógicas para que ele tenha condições de acompanhar os colegas.

O Paraná também aposta na tecnologia e de acordo com (vídeo 8) lança o Programa Presente na Escola como ferramenta no combate à evasão escolar, que consiste em uma base de dados gerando relatórios que pode ser analisados a nível de escola e por série, permitindo ao professor e as instituições uma análise mais rápida para ações direta no combate a evasão escolar. É possível ainda com esse programa um trabalho direcionado por município e por escola, identificando as causas da evasão e a necessidade de parceria para realizar as ações.

Segundo a secretaria de educação do Paraná, o programa vai reunir uma série de estratégias de acompanhamento de frequência e combate ao abandono, desde o monitoramento de frequência até a articulação com a rede de proteção. Cada escola terá um objetivo de frequência. $\mathrm{Ou}$ seja, ao verificar que está com a frequência abaixo de um certo percentual, poderá elaborar ações direcionadas para 
reverter esse quadro. O Presente na Escola funcionará de maneira integrada com o aplicativo Registro de Classe, que permite ao professor realizar a chamada off-line pelo celular. Com essa base de dados, serão gerados relatórios diários por escola e por série. O relatório vai informar, por exemplo, quais são os 10\% alunos mais faltosos. Ainda haverá integração com o aplicativo Escola Paraná, por meio do qual os pais ou responsáveis já recebem mensagens diárias informando se 0 estudante compareceu ou não à escola e conseguem acompanhar a frequência do aluno.

De acordo com o Site Agência de Notícia do Paraná, no dia 13 de maio, quando a iniciativa foi lançada, a média de frequência nas instituições estaduais de ensino era de 85,8\%, em 13 de junho a marca subiu cinco pontos percentuais, alcançando 90,8\%. Durante todo o mês, a média registrada foi de $87,8 \%$ de presença em sala, isso significa 40 mil alunos a mais na sala de aula.

Em Santa Catarina, (vídeo 12) um programa liderado pelo ministério público e justiça, o APOIA, atua no combate à evasão. Os educandos são acompanhados numa rede de atendimento on-line formada pela escola, conselho tutelar e ministério público, e foi criado para conhecer as causas da evasão e evitar o abandono na sala de aula, em média 50\% dos estudantes atendidos pela rede volta para escola. Todo sistema é informatizado, e isso permite um fluxo mais rápido e efetivo no atendimento e ajuda também a garantir melhor qualidade do aprendizado do educando.

De acordo com informação no site do ministério público de Santa Catarina, o APOIA atua com as crianças e jovens de 4 a 17 anos que não completaram o ensino obrigatório, e tem o seguinte objetivo: promover o regresso dessas crianças à escola para que concluam a educação básica; atuar preventivamente para garantir a permanência dos alunos na escola e melhorar a qualidade de ensino, aperfeiçoando políticas públicas voltadas à educação. Funciona através de um sistema on-line integrado de informação entre escola, conselhos tutelares, promotoria e justiça. Com a informatização do programa é possível gerar dados estatísticos com painéis de indicadores de dados que demonstram os motivos da evasão, onde ocorre, faixa etária, e a partir daí buscar políticas públicas para melhorar. O órgão gestor do Programa é o Centro de Apoio Operacional da Infância e da Juventude e as instituições que compõe a rede do APOIA. 
De acordo com site da Radio Vitoria, foi feito uma análise criteriosa e o programa demonstrou resultados eficientes, uma vez que entre 2002 e 2013 , o Programa APOIA possibilitou o retorno de 71.815 alunos à escola. Isso significa uma média de quase 6 mil retornos de alunos por ano, em todo o Estado. Em 2014, com o início do funcionamento do Sistema APOIA Online, obteve-se um resultado histórico: 25.074 alunos retornaram à escola, a partir de um total de 62.793 APOIAs emitidos. Observa-se, assim, que a média anual de retornos à escola quadruplicou a partir da informatização do Programa.

Iniciativa das secretarias de educação municipal, para contenção da evasão escolar

Em Manaus (vídeo 2) o Centro de Atendimento socio-psicopedagógico CESMAP, faz um trabalho de atuação no resgate aos alunos infrequentes, por meio de ações sociais e pedagógicas, com uma equipe de profissionais multidisciplinar. Todos fazendo um trabalho de estimulação do processo de ensino aprendizagem através do lúdico, como também viabilizam a participação mais efetiva da família junto a escola.

De acordo com site da SEDUC Manaus, a Secretaria junto com seu Departamento de Gestão Educacional -
DEGE e Divisão de Apoio a Gestão Escolar - DAGE, através das ações dos Centros Municipais Sociopsicopedagógicos - CEMASPs desenvolve um programa de combate à evasão escolar. Os CEMASPs, inicialmente criados como Programa de Atendimento Sociopsicopedagógico da Rede Municipal de Ensino - PASP, foram modificados para Centro Municipal de Atendimento Sociopsicopedagógico CEMASP através da Lei $\mathrm{n}^{\circ} 1.556$, de 13/01/2011 e tem como missão resgatar os alunos infrequentes, por meio de ações pedagógicas, sociais e fonoaudiológicas. Ainda, segundo o site, além do trabalho preventivo de combate à evasão, a equipe multidisciplinar (pedagogos, psicólogos, fonoaudiólogos, psicopedagogos e assistentes $\quad$ sociais), realizam atendimentos individuais e em grupos, assessoramentos as escolas, palestras, visitas domiciliares e orientação familiar.

Em Salvador, (vídeo 4) impulsionado pelo movimento todos pela educação, criou o Programa Agente da Educação, com o objetivo do combate a evasão escolar. Estudantes de pedagogia integram essa ação, como agentes da educação, fazendo o contato direto com a família e o educando, focando na conscientização desses para a acompanhamento da vida escolar de seus 
filhos, para que garantam a frequência efetiva dos educandos na escola, como também a aproximação das famílias com o ambiente escolar.

De acordo o site do programa, o Programa Agente da Educação promove a aproximação entre a família, escola e comunidade, por meio do desenvolvimento de ações que possibilitam a participação desses familiares no ambiente escolar e o seu envolvimento na rotina estudantil, auxiliando-os no acompanhamento e apoio ao aprendizado dos educandos. Funciona pelo intermédio de estudante de pedagogia (Agente da Educação), que tem o perfil de saber escutar e acolher os diferentes olhares, dúvidas e desejos dos alunos e seus familiares, ajudando a equipe escolar a fortalecer a relação de parceria com as famílias e a comunidade local. Conforme site da secretaria de educação de Salvador, o projeto consiste no monitoramento da frequência escolar e do envolvimento de alunos, pais e comunidade nas atividades realizadas pela escola.

No (vídeo 5) observa-se um programa de redução de evasão escolar desenvolvido pela Secretaria de Educação de Cascavel, que aposta em atividades diferenciadas envolvendo esportes e outros eventos, para o retorno dos educandos evadidos e contenção da evasão. É feito também a identificação da causa do abandono, para que uma equipe multidisciplinar que faz parte do programa, atue junto ao educando e família com o objetivo da permanência desses educandos na escola, que é o principal foco do programa.

De acordo com site Câmara de Cascavel/notícia, o programa existe desde 2011, e foi sugerido pelo Ministério Público, através da Vara da Infância e da Juventude. O objetivo era garantir que fosse realizada uma busca ativa dos alunos, como parte da rede de proteção a todas as crianças e adolescentes residente no Município. Segundo o site Leis Municipais/PR/Cascavel, em fevereiro foi criada a Lei ${ }^{\circ} 6955 / 2019$, que rege em seu artigo $1^{\mathrm{o}}$ a instituição no município de Cascavel - PR do Programa de Prevenção e Combate à Evasão Escolar vinculado e gerenciado pela Secretaria Municipal de Educação em colaboração com as Secretarias de Saúde e Assistência Social. $\mathrm{O}$ artigo $2^{\circ}$ visa a garantia e permanência na escola de crianças e adolescentes em idade escolar obrigatória, promovendo a inclusão e reinserção daqueles em situação de evasão escolar ou infrequências injustificadas e/ou situação de vulnerabilidade. 
As escolas públicas de Contagem MG (vídeo 10), tiveram uma iniciativa que diminuíram muito a taxa de evasão escolar. A iniciativa consiste em visitar a casa dos educandos quando estes faltam, identificar o problema em conversa com os pais e o próprio estudante se for o caso, e buscar soluções junto a escola, sem esquecer de conversar com os pais sobre a importância da educação para o futuro dos seus filhos.

Como indica o Instituto Claro, a evasão escolar era um fator de preocupação nas escolas públicas de Contagem, principalmente nos anos finais do ensino fundamental e diante da situação, a prefeitura desenvolveu o Projeto Articulação Comunitária, que consiste na visita a casa dos alunos faltantes pelos professores, que passam ser os articuladores. A escola também conta com conselho tutelar, lideranças de bairro, Defesa Social, Direitos Humanos, Saúde e Departamento de Psicologia da Pontifícia Universidade Católica (PUC-Betim). O resultado é que o rendimento dos alunos melhorou sensivelmente desde o início do programa, em agosto de 2015, observouse a redução da evasão escolar e da indisciplina, como também o aumento nas notas dos educandos.

Macaé (vídeo 11) realiza ações para o combate à evasão escolar, entre elas o mutirão de atendimento aos pais ou responsáveis por estudantes infrequentes, que são convocados por carta antecipadamente. $\mathrm{Na}$ oportunidade, também, são comunicados das penalidades que estão passíveis se não manterem os filhos na escola. Essas ações fazem parte do projeto escola legal, frequência total. $\mathrm{O}$ mutirão tem parceria com a promotoria da juventude, conselho municipal da defesa dos direitos da criança e do adolescente e conselhos escolares. O mutirão ocorre três vezes ao ano e estima-se que $80 \%$ dos alunos voltam a frequentar a escola.

De acordo com site da prefeitura de Macaé, tudo começou com o I Fórum Municipal de Segurança Escolar, realizado na Cidade Universitária, daí surgiu a proposta para criação de uma força tarefa, com integrantes do segmento das áreas de Educação e Segurança para promover a reinserção dos alunos nas escolas, pois a violência estava como um dos principais fatores da Evasão escolar na região. A ação é desenvolvida pelas equipes do Serviço Social, Orientação Educacional e o Bolsa Família, com parceria do Conselho Tutelar, para orientar as famílias sobre a importância da permanência dos alunos, incentivando assim, o interesse na educação e integração da comunidade escolar. Para 
realizar o mutirão, a equipe da Secretaria de Educação recebe a Ficha de Comunicação ao Aluno Infrequente (Ficai), material encaminhado ao Conselho Tutelar e equipes do Serviço Social, Orientação Educacional e Supervisão de Ensino, além da Orientação Educacional, responsável por acionar as famílias dos estudantes ausentes.

\section{Ações de incentivos aos educandos, na busca da prevenção da evasão escolar}

Conforme (Vídeo 3) dois projetos de entidades sem fins lucrativos, estão melhorando a frequência dos educandos em São José do Rio Preto: o Projeto Jovem Aprendiz, que premia os alunos com as melhores notas, no final do ano, e o Projeto Camerata Jovem, que possibilita aos aluno não faltosos e com bom rendimentos, aulas de música, artes plásticas e teatro. Em ambos os projetos os educandos dizem sentirem-se estimulados.

Segundo Ação Social Cooperada, a Associação Artística e Cultural do Interior Paulista - AACIP (Camerata Jovem Beethoven), fundada em maio de 2011, é um projeto sociocultural, socioeducativo e de apoio profissional, criado com o objetivo de formar cidadãos de bem por meio das artes e da música, além de artes plástica e teatro, atendo alunos de 5 a 29 anos. De acordo com o
Diário da Região, o objetivo da Camerata Jovem Beethoven é ser um projeto de referência pela qualidade em educação e cultura, reconhecida pelos resultados do processo de ensino e aprendizagem.

No (vídeo 6) é exposto, através de uma conversa entre o surfista Rico e a voluntária Luiza Ren, um trabalho através do Projeto Notas Azuis, que funciona estimulando os educandos evadidos a voltarem a estudar. $\mathrm{O}$ estímulo vem com oportunidade de viagens a partir de um programa de recompensa, em uma ação na Rocinha, por exemplo, 10 jovens foram contemplados para uma viagem a Florianópolis. O trabalho é feito com jovens da comunidade da Rocinha, Cesar Maia e Maré. Em consulta ao site do projeto, verifica-se que o objetivo é incentivar as crianças e adolescentes de comunidades carentes a melhorarem seu desempenho acadêmico, por meio de premiações com viagens e oportunidades esportivas, dos que atingem boas notas na escola. O projeto é composto por voluntários que se engajam com intuito de reduzir a evasão escolar.

Em Campo Mourão-PR (vídeo 13), uma ação da promotoria reúne atletas e ex atletas com exemplo de superação, para convencer os jovens a não deixarem a escola, o objetivo é diminuir o alto índice de evasão escolar na cidade. Atletas do 
Atlético e do Coritiba, esqueceram as diferenças e uniram-se pela causa, compareceu ao evento também o maratonista paranaense Vanderlei Cordeiro de Lima, que falou de sua trajetória de boia fria a campeão olímpico e da relação do esporte com a educação, estimulando aos jovens entenderem que frequentando a escola é possível um futuro promissor.

O Projeto Jovem que Está Mudando o Mundo ( vídeo 14), desenvolvido pela escola Gilka Drumond, tem como objetivo o combate a evasão escolar, e entre outras atividades, promove, com apoio dos professores de educação física, campeonatos internos de futsal, apostando no esporte como meio para conter a infrequência dos educandos. O professor de educação física Maíron Cesar Gomes Santos, enfatiza que o projeto consiste em atrair cada vez mais os educandos para escola, e utiliza a prática esportiva com ferramenta.

Duas escolas em Minas gerais (vídeo 15), enfrenta o combate a evasão escolar, utilizando jogos de tabuleiros como instrumento. A Escola Carlos Drumond de Andrade desenvolve um projeto a 24 anos, que consiste em utilizar o jogo de xadrez, possibilitando a saída das aulas tradicionais e desenvolvendo nos educandos habilidades como: raciocínio lógico, estratégia, concentração, o respeito aos pares, aprender ganhar e perder, ajudando também no processo de tomada de decisões, entre outros elementos, tudo isso melhora seu rendimento escolar e a frequência.

Na Escola Estadual Areda Franco, a adesão do projeto com utilização de jogos tem pouco mais de um ano, e surgiu através de um desafio proposto em um prêmio de Educação - reduzir a evasão escolar. O projeto ficou em segundo lugar, e a escola terá uma sala exclusiva para aprender brincando, com a disponibilização de 60 jogos onde os alunos aprende sobre biologia, história, matemática, além de lições sobre estratégia, raciocínio lógico e empreendedorismo, assim ninguém mais vai querer abandonar a escola.

Diante dos relatos dos vídeos, observa-se iniciativas independentes de estados, municípios, professores, ongs, etc. numa tentativa sanar o fenômeno da evasão, cada uma dentro das suas limitações e a partir do entendimento de como sua ação vai conter a evasão escolar. Todavia, de um modo geral três fatores foram os principais parâmetros que serviram para a execução dos programas e ações: a família no tocante ao seu compromisso de manter o filho na escola, 
e o educando, no que se refere a vontade de estar na escola e a própria escola.

A responsabilização da família com a infrequência do educando é legitima, de acordo com o artigo 205 da Lei de Diretrizes e Bases da Educação Nacional (Lei 9394/96), “a educação é dever da família e do estado e assegura que a educação é um direito de todos ingressar na escola e nela permanecer" (BRASIL, 1996). No entanto, não é apenas o governo disponibilizar a escola, e os pais manter os filhos na escola, é preciso que todos os fatores necessários no que concerne a viabilidade da escola para o educando e as condições do educando para ir à escola, sejam assegurados para garantia desse direito.

\section{CONCLUSÃO}

O presente estudo buscou vídeos compartilhado no sitio do YouTube, que tivessem ações voltada a retenção da evasão escolar, obtivendo uma grande quantidade desses recursos, a parti daí foram observados iniciativas de variados setores, como: secretarias estaduais de educação; secretarias municipais de educação; ministério público a nível estadual e municipal; a escola; o professor e entidades sem fins lucrativos, cada um deles com variados tipos de propostas.
Sabe-se que são vários os fatores, internos e externos à escola, como aulas monótonas, estrutura física da escola ruim, falta de comunicação família/escola, drogas, gravidez precoce, necessidade de trabalhar, falta de transporte escolar, entre tantos outros, que influenciam diretamente na infrequência dos educandos. Segundo Dourado (2005), uma educação com qualidade social é caracterizada por um conjunto de fatores intra e extraescolares que se referem às condições de vida dos alunos e de suas famílias, ao seu contexto social, cultural e econômico e à própria escola - professores, diretores, projeto pedagógico, recursos, instalações, estrutura organizacional, ambiente escolar e relações intersubjetivas no cotidiano escolar.

As Secretarias estaduais e municipais de educação tem ações voltadas mais com as questões pedagógicas, já o ministério público visa uma rede de acompanhamento do educando para que seja garantida sua permanência na escola, professores procuram realizar atividades que sejam atrativas para os estudantes, e as entidades apostam em oferecem atividades na área de cultura esporte e lazer, como recompensa para os assíduos na sala de aula. 
A pesquisa teve suas limitações, pois o uso de redes sociais, o YouTube, não dispõem de protocolos que norteiam o seu desenvolvimento metodológico, daí a dificuldade em encontrar recursos audiovisuais acerca da temática específica trabalhada, e as informações disponíveis para o material estudado deixam a desejar. Mesmo assim contribui, no sentido de averiguar os esforços desse conjunto de setores para viabilizar ações, através dos projetos e programas, voltadas para o combate a evasão escolar.

Por fim compreende-se neste artigo, de acordo com vídeos selecionados

\section{REFERÊNCIAS}

DANTAS, Tiago. "Youtube"; Brasil Escola. Disponível em: https://brasilescola.uol.com.br/informatic a/youtube.htm. Acesso em 08 de outubro de 2019.

DOURADO, Luiz Fernandes. Elaboração de políticas e estratégias para a prevenção do fracasso escolar - Documento Regional BRASIL: Fracasso escolar no Brasil: políticas, programas e estratégias de prevenção ao fracasso escolar, 2005. https://www.oei.es > quipu > brasil > sistema $>$ nacional $>$ formacion $>$ professor es.

Fundo das Nações Unidas para a Infầncia (UNICEF). Cenário da exclusão escolar no Brasil.2017. Disponível em: $<$ https://www.unicef.org/brazil/media/48 1/file/Cenario_da_exclusao_escolar_no Brasil.pdf $>$. Acesso em:25 de mar. $202 \overline{0}$. no sítio do YouTube, a criação de várias formas de enfrentamento através de projetos e programas, a nível estadual, municipal, escolar e individual, com potencial de atacar as causas, superando dessa forma os obstáculos e dificuldades, para a diminuição da evasão e do abandono escolar. Esses variados setores com iniciativas diferentes sendo aplicadas nas escolas, mostra a inexistência de uma forma, de modo a atingir todas as escolas, que possa reduzir os índices de evasão e abandono escolar de forma ampla, não pontual.

LIMA, Cristina Maria Garcia de et al .Pesquisa etnográfica: iniciando sua compreensão. Rev. Latino-Am. Enfermagem, Ribeirão Preto, v. 4, n. 1, p. 21-30,Jan. 1996 . Disponível em: $<$ http://www.scielo.br/scielo.php?script=s ci_arttext\&pid=S0104$11691996000100003 \& \operatorname{lng}=$ en\&nrm=iso $>$ . Acesso em: 23 de set. 2019.

Maria Cristina Schefer [1], Gelsa Knijnik [2] Construindo uma pesquisa do "tipo etnográfico" na educação. Revista principia, n. 28, p, 104-110, 2015.

Secretaria de Educação do Estado do Paraná. Disponível em: $<$ http://www.educacao.pr.gov.br/modules $/$ noticias/article.php?storyid $=8187 \&$ tit $=\mathrm{G}$ overno-adota-novas-medidas-paracombate-ao-abandono-escolar $>$ Acesso em: 30 de set. 2019.

Agência de Notícia do Paraná. Combate ao abandono escolar apresenta resultados positivos. Portal eletrônico. Disponível em: 
$<$ http://www.aen.pr.gov.br/modules/notic ias/article.php?storyid $=102908 \& \mathrm{tit}=\mathrm{Com}$ bate-ao-abandono-escolar-apresentaresultados-positivos $>$ Acesso em: 30 de set. 2019.

Governo de Pernambuco. Secretaria de Educação e de Esporte. Portal eletrônico. Disponível em:

$<$ http://www.educacao.pe.gov.br/portal/? pag $=1 \&$ men $=70>$.Acesso em: 30 de set. 2019.

Assembleia Legislativa do Estado de Pernambuco. Lei complementar 125/2008. Disponível em: $<$ https://legis.alepe.pe.gov.br/texto.aspx?i $\mathrm{d}=5148 \&$ tipo $=$ TEXTOATUALIZADO $>$. Acesso em: 30 de set. 2019.

Presidência da República. Constituição da República Federativa do Brasil, 1988. Disponível em:

$<$ http://www.planalto.gov.br/ccivil_03/co nstituicao/constituicao.htm>. Acesso em: 30 de set. 2019.

Presidência da República. Lei de

Diretrizes e Bases da Educação - 9394/96

Disponível em:

$<$.http://www.planalto.gov.br/ccivil_03/le is/19394.htm>. Acesso em: 16 de out. 2019.

Secretaria de Educação do Estado de Piauí. Mobieduca.Me. Portal eletrônico. Disponível em:

$<$ https://seduc.pi.gov.br/matricula/mobied uca.php. Consulta em 30/09/2019>.

Acesso em: 20 de nov. 2019.

Governo do Estado do Piauí.

Mobieduca.Me. Portal eletrônico.

Disponível em:

$<$ http://www.pi.gov.br/materia/educacao/ seduc-vai-expandir-mobieducame-paratodas-as-escolas-8930.html >. Acesso em: 20 de nov. 2019.
Câmara de Cascavel. Programa de prevenção e combate à evasão escolar vai virar lei. Portal eletrônico. Disponível em:

$<$ https://www.camaracascavel.pr.gov.br/n oticias/item/7768-programa-deprevencao-e-combate-a-evasao-escolarvai-virar-lei.html> Acesso em: 09 de out. 2019.

Leis Municipais/PR/Cascavel. Lei ${ }^{\circ}$ 6955 de 19 de fevereiro de 2019. Portal eletrônico. Disponível em:

$<$ https://leismunicipais.com.br/a/pr/c/casc avel/lei-ordinaria/2019/696/6955/leiordinaria-n-6955-2019-cria-e-implanta-oprograma-de-prevencao-e-combate-aevasao-escolar-no-municipio-decascavel-pr-e-da-outras-providencias>. Acesso em: 09 de out. 2019.

Prefeitura de Macaé - RJ. Fórum de Segurança Escolar une forças no combate à evasão. Portal eletrônico. Disponível em:

$<$ http://www.macae.rj.gov.br/semed/leitu $\mathrm{ra} /$ noticia/forum-de-seguranca-escolarune-forcas-no-combate-a-evasao>. Acesso em: 09 de out. 2019.

Prefeitura de Manaus. Secretaria Municipal de Educação. Centros Municipais Sociopsicopedagógicos CEMASPs. Portal eletrônico. Disponível em:

$<$ http://semed.manaus.am.gov.br/cemasps />. Acesso em: 09 de out. 2019.

Prefeitura de Salvador/Programa agente da educação. Agente da Educação aproxima escola, família e comunidade. Portal eletrônico. Disponível em: $<$ http://agentedaeducacao.salvador.ba.gov .br/projetos.php. > Acesso em: 07 de jun. 2019.

Secretaria de Educação de Salvador. Agente da Educação. Portal eletrônico. Disponível em:

$<$ http://educacao.salvador.ba.gov.br/progr 
ama-projeto/agente-da-educacao/>. Acesso em: 09 de out. 2019.

Ação Social Cooperada. Entidades apoiadas. Portal eletrônico. Disponível em:. <http://fundoasc.com.br/entidadesapoiadas/sao-jose-do-rio-preto/cameratajovem-beethoven $>30 / 09 / 2019$. Acesso em: 09 de out. 2019.

Instituto Claro. Professores de Contagem visitam alunos contra a evasão escolar. Portal eletrônico. Disponível em:
$<$ https://www.institutonetclaroembratel.o rg.br/educacao/nossasnovidades/reportagens/professores-decontagem-visitam-alunos-contra-aevasao-escolar/>. Acesso em: 30 de set. 2019.

Queiroz, L. D. Um estudo sobre a evasão escolar: para se pensar na inclusão escolar. Disponível em: $<$ www.25reuniao.anped.org.br > lucileidedomingosqueirozt13 $>$. Acesso em: 09 de out. 2019. 